\title{
PGRN exerts inflammatory effects via SIRT1-NF-KB in adipose insulin resistance
}

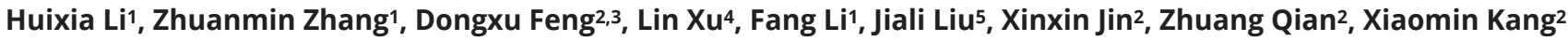 \\ and Hongzhi Sun 1 \\ 1Department of Physiology and Pathophysiology, School of Basic Medical Sciences, Xi'an Jiaotong University Health Science Center, Xi'an, Shaanxi, China \\ ${ }^{2}$ Hong Hui Hospital, Xi'an Jiaotong University School of Medicine, Xi'an, Shaanxi, China \\ ${ }^{3}$ Center for Translational Medicine, The First Affiliated Hospital of Medical School of Xi'an Jiaotong University, Xi'an, Shaanxi, China \\ ${ }^{4}$ Department of Endocrinology, The Affiliated Guangren Hospital, Medical School of Xi'an Jiaotong University, Xi'an, Shaanxi, China \\ ${ }^{5}$ Department of Clinical Laboratory, Xi'an Jiaotong University Second Affiliated Hospital, Xi'an, Shaanxi, China
}

Correspondence should be addressed to H Li or H Sun: lihuixia@mail.xjtu.edu.cn or sunhongzhi@mail.xjtu.edu.cn

\begin{abstract}
Progranulin (PGRN), a multifunctional protein implicated in embryonic development and immune response, was recently introduced as a novel marker of chronic inflammation related with insulin resistance in obesity and type 2 diabetes mellitus. However, the potential mechanisms of PGRN on insulin signaling pathways are poorly understood. In this study, PGRN mediated the chemotaxis of RAW264.7, impaired insulin action and stimulated production of inflammatory factors in adipocytes, which was accompanied by increased c-Jun N-terminal kinase (JNK) activation and serine phosphorylation of insulin receptor substrate-1. PGRN knockdown partially led to an increase in insulin action as well as a decrease in the JNK activation and extracellular signal-regulated kinase phosphorylation in cells exposed to tumor-necrosis factor- $\alpha$ (TNF- $\alpha$ ). Meanwhile, PGRN treatment resulted in an elevation of transcription factor nuclear factor $\kappa B$ (NF-kB) nuclear translocation and acetylation, and increased $\|-1 b\|$,6 , Tnf-a expression, whereas NF-kB inhibition reversed PGRN-induced insulin action impairment and inflammatory gene expression. Finally, we showed that sirtuin 1 (SIRT1) expression was downregulated by PGRN treatment, whereas SIRT1 overexpression improved PGRN-induced insulin resistance, NF-kB activation, and inflammatory gene expression. Our results suggest that PGRN regulates adipose tissue inflammation possibly by controlling the gain of proinflammatory transcription in a SIRT1-NF-kB dependent manner in response to inducers such as fatty acids and endoplasmic reticulum stress.
\end{abstract}

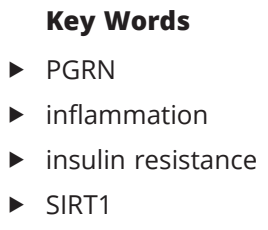

Journal of Molecular Endocrinology (2020) 64, 181-193

\section{Introduction}

Progranulin (PGRN), also known as granulin/epithelin precursor (GEP) or PC cell-derived growth factor, is a multifunctional regulatory protein that mediates cell cycle progression and cell motility in several processes, including immune response, wound healing, tumorigenesis, and neuro-proliferative and degenerative diseases (Cenik et al. 2012, Arechavaleta-Velasco et al. 2017, Chitramuthu et al. 2017). This protein is thought to be upregulated in both serum and synovial fluid in patients with rheumatoid arthritis (Yamamoto et al. 2014, Cerezo et al. 2015), while PGRN-deficient mice are more susceptible to neuroinflammation and inflammatory 
arthritis, respectively (Tang et al. 2011, Martens et al. 2012). However, loss of PGRN led to accelerated disc degeneration, along with decreased expression of IL-10 and increased expression of IL-17 (Wang et al. 2018), and its deficiency also exacerbates neuroinflammatory responses related to activated microglia in aged animals (Ma et al. 2017). Likewise, when applied to a cutaneous wound, PGRN increased the accumulation of neutrophils, macrophages, blood vessels, and fibroblasts in the wound (He et al. 2003). Despite such an intricate involvement in the inflammatory response, considerable effort has gone into ascertaining that PGRN also has proinflammatory effects in obesity and insulin-resistant diabetes mellitus.

Recent studies have identified PGRN as an important determinant of glucose homeostasis and an increase in serum PGRN levels that were closely related to measures of adiposity, metabolic parameters, inflammatory marker and insulin resistance indices (Hossein-Nezhad et al. 2012, Alissa et al. 2017), potentially contributing to the pathogenesis of type 2 diabetes mellitus (T2DM). In particular, circulating PGRN is positively correlated with macrophage infiltration in omental AT of T2DM subjects and implicated in inflammation and atherosclerosis in subjects with metabolic syndrome (Youn et al. 2009, Yoo et al. 2013). In AT innate immunity, Toll-like receptor (TLR) 9 agonists decreased and TLR1/2 ligands increased PGRN expression (Schmid et al. 2019). Systemic administration of PGRN to rodents impaired glucose tolerance through IL-6 expression, whereas PGRN deficiency protects from highfat diet (HFD)-induced insulin resistance and body weight gain (Matsubara et al. 2012). Likewise, we have reported that treatment of tumor-necrosis factor receptor-1 blocking peptide nullified the detrimental effects of PGRN on insulin action (Liu et al. 2015). Although the emergence of PGRN as a regulator of energy metabolism, much less is known about the role of PGRN on chronic inflammation in AT.

Sirtuin 1 (SIRT1) is an essential nutrient-sensing histone deacetylase, which is upregulated by caloric restriction and reduced by overfeeding. This protein is supposed to protect insulin sensitivity, promote energy expenditure, and reduce the risk of hepatic steatosis (Peng et al. 2018). Recent studies suggest that SIRT1 regulated angiogenesis and inflammation in WAT (Luo et al. 2016), and its inactivation led to macrophage recruitment to AT possibly resulting from transcription factor nuclear factor $\kappa \mathrm{B}(\mathrm{NF}-\kappa \mathrm{B})$ activation (Gillum et al. 2011). These findings implicated SIRT1 regulated insulin signaling partially through the anti-inflammatory actions mediated by NF- $\mathrm{B}$ inhibition (Yoshizaki et al. 2009). More recently, PGRN treatment decreased SIRT1 expression and increased the acetylation of the forkhead transcription factor FOXO1 in cholangiocytes, whereas overexpression of SIRT1 in vitro prevented the proliferative effects of PGRN (Frampton et al. 2012). Besides, our previous results showed that NF- $\kappa \mathrm{B}$ activation is required for PGRN to inhibit insulin signaling in hepatocytes and to stimulate growth plate chondrogenesis (Wu et al. 2011). Since SIRT1 can modulate NF- $\mathrm{kB}$-dependent transcription of inflammatory responses and metabolic pathways (Yeung et al. 2004), we therefore considered whether PGRN could inhibit insulin sensitivity and exert proinflammatory effects via SIRT1-NF-кB pathway in AT.

\section{Materials and methods}

\section{Agents}

Recombinant mouse PGRN was prepared as previously described (Liu et al. 2015). SRT1720 (S1129) was purchased from Selleck Chemicals. EX527 (E70734) were purchased from Sigma. Anti-PGRN (sc-28928), anti-phospho-c-JUN (sc-822), anti-phospho-NF-кB p65 (sc-136548), anti-NF-кB p65 (sc-372), anti-H3 (sc-10809), anti-SIRT1 (sc-135792), anti-F4/80 (sc-377009) and anti-GAPDH (sc-365062) were from Santa Cruz Biotechnology. Pyrrolidine dithiocarbamate (PDTC, S1808) and anti-c-JUN (AF1612) were from Beyotime Biotechnology. Anti-insulin receptor (IR, ab131238), anti-phospho-IR (ab60946), anti-phospho-extracellular signal-regulated kinase (ERK1/2, ab201015), anti-ERK1/2 (ab115799), anti-NF-кB p65 (acetyl K310) (ab19870), antiinsulin receptor substrate 1 (IRS-1, ab131487), anti-IRS1 (phospho Y896) (ab46800), anti-IRS1 (phospho S307) (ab1194), anti-phospho-Akt (ab81283), anti-Akt1/2/3 (ab179463) and anti-acetyl lysine (ab80178) were from Abcam. Tumor-necrosis factor- $\alpha$ (TNF- $\alpha, 11271156001)$ and collagenase I (1148089) were from Roche.

\section{Animals}

Male C57BL/6J mice (6 week old) were group-housed at $22-24^{\circ} \mathrm{C}$ on a 12 -h light/dark cycle with the lights on at 8:00 $\mathrm{h}$ and had free access to food and water. For obesity studies, mice were fed a high-fat-diet (HFD) containing $60 \%$ fat by weight (D12492, Research Diets) for 8 weeks. For PGRN-exposure studies, 6-week-old male mice fed with normal rodent chow (ND, Harlan Teklad, 2018S) took $1 \mu \mathrm{g} / \mathrm{g} /$ day dose of PGRN intraperitoneally for 4 weeks (6 to 8 per group). Body weight and tail blood glucose were monitored every week. After 4 weeks, mice received an ip injection of insulin ((Sigma-Aldrich, 91077C), 
$2 \mathrm{IU} / \mathrm{kg}$ ) for insulin signaling, and 15 min later, all mice were killed, then their blood and AT were obtained and stored at $-80^{\circ} \mathrm{C}$ for subsequent analysis. Blood glucose levels were measured by a handheld glucometer (Bayer) and serum insulin levels were measured by an ultrasensitive mouse-specific ELISA kit (ab100578, Abcam) with intra- and interassay coefficients of variation of 3.9-6.6\% and 5.6-5.8\%, respectively. Peripheral serum was subject to ELISA using standard kits (R\&D Systems, Inc.) for PGRN. Animal care and experimental procedures performed in this study were approved by the Institutional Animal Ethics Committee for the Care and Use of Laboratory Animals.

\section{Metabolic tests}

Glucose tolerance testing (GTT) was performed after the mice were fasted overnight. A total of $2 \mathrm{~g} / \mathrm{kg}$ glucose was administrated through an ip injection, and blood glucose was measured at the indicated time points. Insulin tolerance testing (ITT) was performed after the animals had fasted for $4 \mathrm{~h}$. Then, $0.75 \mathrm{U} / \mathrm{kg}$ insulin was administered via ip injection and blood glucose was measured at the indicated time points.

\section{ELISA}

Collected murine serum underwent ELISA using murine ELISA kits according to the manufacturers' instructions. PGRN- and TNFo-specific ELISA kit were obtained from R\&D Systems (MPGRN0 and MAT00B). IL-6 (D720007) and IL-1 $\beta$ (D720335) were obtained from Sangon Biotech. IL-6, TNF- $\alpha$, and IL-1 $\beta$ levels were also detected in conditional media of adipocytes.

\section{Hematoxylin and eosin (H\&E) staining and immunohistochemistry}

Fresh fat samples $(5 \times 5 \times 5 \mathrm{~mm})$ were collected and fixed in $4 \%$ paraformaldehyde. The tissue slides were obtained through serial cross-section cutting at $5 \mu \mathrm{m}$ to $8 \mu \mathrm{m}$ thickness and stained with H\&E. Thin tissue slides $(5 \mu \mathrm{m})$ were deparaffinized, blocked, and incubated overnight at $4^{\circ} \mathrm{C}$ with PGRN antibody, F4/80 antibody and SIRT1 antibody. Subsequently, an ABC kit (Santa Cruz Biotechnology, sc-2018; Zhongshan Biotechnologies, SP-9001) and DAB exposure were used for detection.

\section{Stromal vascular fraction (SVF) isolation}

Epididymal fat pads excised from mice fed NC or HFD were weighted, rinsed three times in $\mathrm{PBS}$, and then minced as previously described (Yoshizaki et al. 2009). Tissue suspensions were centrifuged at $500 \boldsymbol{g}$ for $5 \mathrm{~min}$, and then treated with collagenase $(1 \mathrm{mg} / \mathrm{mL})$ for $30 \mathrm{~min}$ at $37^{\circ} \mathrm{C}$ with shaking. The cell suspensions were filtered through a $100 \mu \mathrm{m}$-pore-size filter and centrifuged at $700 \boldsymbol{g}$ for $5 \mathrm{~min}$. SVF pellets and adipocyte fraction were then analyzed for mRNA.

\section{Cell culture and treatment}

RAW264.7 (a murine macrophage cell line) and 3T3-L1 cells were purchased from American Type Culture Collection and cultured in DMEM (HyClone, SH30243) with 10\% fetal bovine serum (FBS) (Gibco Invitrogen, 16000044), $100 \mathrm{U} / \mathrm{mL}$ penicillin, and $100 \mu \mathrm{g} / \mathrm{mL}$ streptomycin. 3T3-L1 cells were differentiated by treating $90-95 \%$ confluent cells in DMEM containing $(0.5 \mathrm{mM}$ isobutylmethylxanthine (Sigma-Aldrich, I-5879), $1 \mu \mathrm{M}$ dexamethasone (SigmaAldrich, D1756), $10 \mu \mathrm{g} / \mathrm{mL}$ insulin, and DMEM with $10 \%$ FBS) for 2 days. Two days after the induction, cells were switched to the maintenance medium containing 10\% FBS and $10 \mu \mathrm{g} / \mathrm{mL}$ insulin, which was changed every 2 days thereafter until analysis. 3T3-L1 adipocytes from different experiment conditions were stimulated with 100 $\mathrm{ng} / \mathrm{mL}$ PGRN for $48 \mathrm{~h}$, or $10 \mathrm{ng} / \mathrm{mL}$ of TNF- $\alpha$ for $4 \mathrm{~h}$, or $100 \mu \mathrm{M}$ pyrrolidine dithiocarbamate (PDTC, a specific NF-KB inhibitor) for $30 \mathrm{~min}$ prior to stimulation with TNF- $\alpha$. For insulin signaling, cells were stimulated with $10 \mathrm{nM}$ insulin for $10 \mathrm{~min}$ before collection.

\section{Migration assay}

The migration rate of RAW264.7 cells was determined using a Transwell@ chamber (Corning) with $8 \mu \mathrm{m}$ pore filters. PGRN dissolved in DMEM medium containing $0.5 \%$ FBS was added in the bottom chamber at indicated concentration. $2 \times 10^{5} /$ well RAW264.7 cells were added to the upper chamber. As a control, PGRN was boiled for $10 \mathrm{~min}$. After $16 \mathrm{~h}$ incubation at $37^{\circ} \mathrm{C}$ in a $5 \% \mathrm{CO}_{2}$ humidified atmosphere, non-migrating cells were removed from the upper surface of the insert using a cotton swab. Cells were fixed with $4 \%$ formalin and stained with hematoxylin. Migrated cells in the lower chamber were counted in four randomly selected microscopic fields.

\section{RNA interference, DNA constructs transfection and viruses production}

3T3-L1 cells were transfected with siRNA targeted for mouse $N f_{k} b-p 65$ (sc-29411, Santa Cruz Biotechnology), 
mouse Pgrn (sc-39262, Santa Cruz Biotechnology) using Lipofectamine 2000 (Invitrogen, 11668027). A siRNA consisting of a scrambled sequence of similar length was transfected similarly to control siRNA. The constructs were subcloned into a pMSCV-puro retroviral vector or a pcDNA3.1 using full-length SIRT1 (Genechem Co, Shanghai, China). 3T3-L1 cells were transfected with pcDNA3.1-SIRT1 or empty vector using Lipofectamine 2000 (Invitrogen), according to the procedure recommended by the manufacturer. For retrovirus production, Phoenix packaging cells were transfected at 60-70\% confluence by Lipofectamine 2000 with $10 \mu \mathrm{g}$ of retroviral vectors. After $48 \mathrm{~h}$, the viral supernatant was harvested and filtered. Cells were incubated with the viral supernatant for two days, supplemented with $8 \mathrm{mg} / \mathrm{mL}$ polybrene. Subsequently, puromycin was used for selection.

\section{RNA isolation and quantitative real-time PCR (RT-qPCR)}

Total RNA was isolated and purified from treated cells or AT by TRIzol reagent (Invitrogen, 15596-026) according to the manufacturer's instruction. First-strand cDNA synthesis and RT-qPCR was performed as previously described (Li et al. 2015). Primer sequence information is available upon request. Each sample was performed in duplicate and experiments repeated three times.

\section{In vitro glucose uptake assay}

The procedure for evaluating glucose transport was performed as previously described (Li et al. 2015). Briefly, after transfer of cells to medium without glucose, adipocytes were incubated with $100 \mathrm{nM}$ insulin for $15 \mathrm{~min}$, then glucose transport was determined as uptake of $50 \mu \mathrm{M}(10 \mu \mathrm{Ci} / \mathrm{mL})$ 2-deoxy-D-[1-3H] glucose (2-DG), and then incubated $30 \mathrm{~min}$. Uptake was linear for at least $30 \mathrm{~min}$.

\section{Western blotting}

Western blotting experiments were performed as described previously ( $\mathrm{Wu}$ et al. 2011). Cells and tissues were lysed using RIPA buffer (50 mM Tris-HCl, pH7.9, $150 \mathrm{mM} \mathrm{NaCl}, 0.5 \mathrm{mM}$ EDTA, and $0.5 \% \mathrm{NP}-40$, and $0.1 \mathrm{mM}$ PMSF). Proteins were separated by $10-15 \%$ sodium dodecylsulfate PAGE; separated proteins were then electronically blotted onto polyvinylidene fluoride membranes. The membranes were then blocked and subsequently incubated with designated primary antibodies overnight at $4^{\circ} \mathrm{C}$. At last, the blots were visualized by an enhanced chemiluminescence (ECL, Millipore, WBKLS0100) detection system.

\section{Study approval}

The animal experiments were approved by the Animal Experiment Administration Committee of Xi'an Jiaotong University Health Sicence Center in Shannxi, People's Republic of China.

\section{Statistical analysis}

Statistical analyses were performed using SPSS 17.0 software. Data are means \pm S.D. Statistical analysis was performed using an unpaired, two-tailed Student $t$ test between the two groups or one-way ANOVA followed by the least significant difference (LSD) post hoc tests for more than two groups. Differences were considered significant when the $P$ value was $<0.05$.

\section{Results}

\section{Upregulation of adipose PGRN expression in obesity}

Our previous study has shown that PGRN expression is upregulated in omental AT in subjects with metabolic syndrome and likely to be novel adipokine mediating insulin sensitivity. Accordingly, we measured in vivo PGRN protein expression in 14-week HFD-fed mice, which are obese and insulin resistant (data not shown). Our data (not shown) show a dramatic elevation of serum and AT PGRN protein content in obese mice compared with the controls. Noticeably, this increase in visceral fat of obese mice appeared to be more pronounced compared with s.c. fat. Moreover, we also observed a marked comparable elevation of Pgrn mRNA in the adipocyte fraction and SVF components from obese mice. Further immunostaining also demonstrated an increase in PGRN protein in AT from obese mice (data not shown), suggesting that the increased PGRN expression in AT might contribute to obesity disorders.

\section{PGRN induces chemotactic activity and impairs insulin action in vitro}

The findings (data not shown) raises the question concerning the potential role of PGRN in low-grade inflammation and insulin resistance seen in the AT of obese rodents and humans. To investigate whether PGRN 
has a causal role on monocyte recruitment into AT, we first performed Raw 264.7 cell-based migration assays. PGRN treatment promoted cell migration with a maximal migration capacity at a concentration of $100 \mathrm{ng} / \mathrm{ml}$ (Fig. 1A and $\mathrm{B}$ ). These findings suggest that PGRN might be a chemotactic factor for macrophages infiltrated in AT of obese subjects. What's more, we also observed significant increases in several pro-inflammatory genes including Il-6, Tnf $\alpha$, and Il-1b in adipocytes (Fig. 1C). To further assess whether PGRN affects glucose metabolism, we measured 2-DG uptake in 3T3-L1 adipocytes treated with or without PGRN. As Fig. 1D illustrates, PGRN treatment led to an $11.7-34.4 \%$ decrease in insulinstimulated glucose transport compared to controls.
The blunted responsiveness of the insulin signaling in adipocytes is often manifested by decreased tyrosine phosphorylation of IRS- 1 and elevated serine phosphorylation of IRS-1. Indeed, PGRN led to decreased insulin-stimulated tyrosine phosphorylation of IRS-1 and its reduced downstream phosphorylation of AKT (Fig. 1E), which was accompanied by increased IRS-1 Serine307 phosphorylation (Fig. 1F). Since Serine307 is a well-known target of c-Jun N-terminal kinase (JNK, also known as SAPK; stress-activated protein kinase), we then hypothesized that PGRN in adipocytes might enhance inflammatory pathway activity, leading to increased serine phosphorylation of IRS-1. As expected, Fig. 1F shows that PGRN treatment also led to an increase in JNK
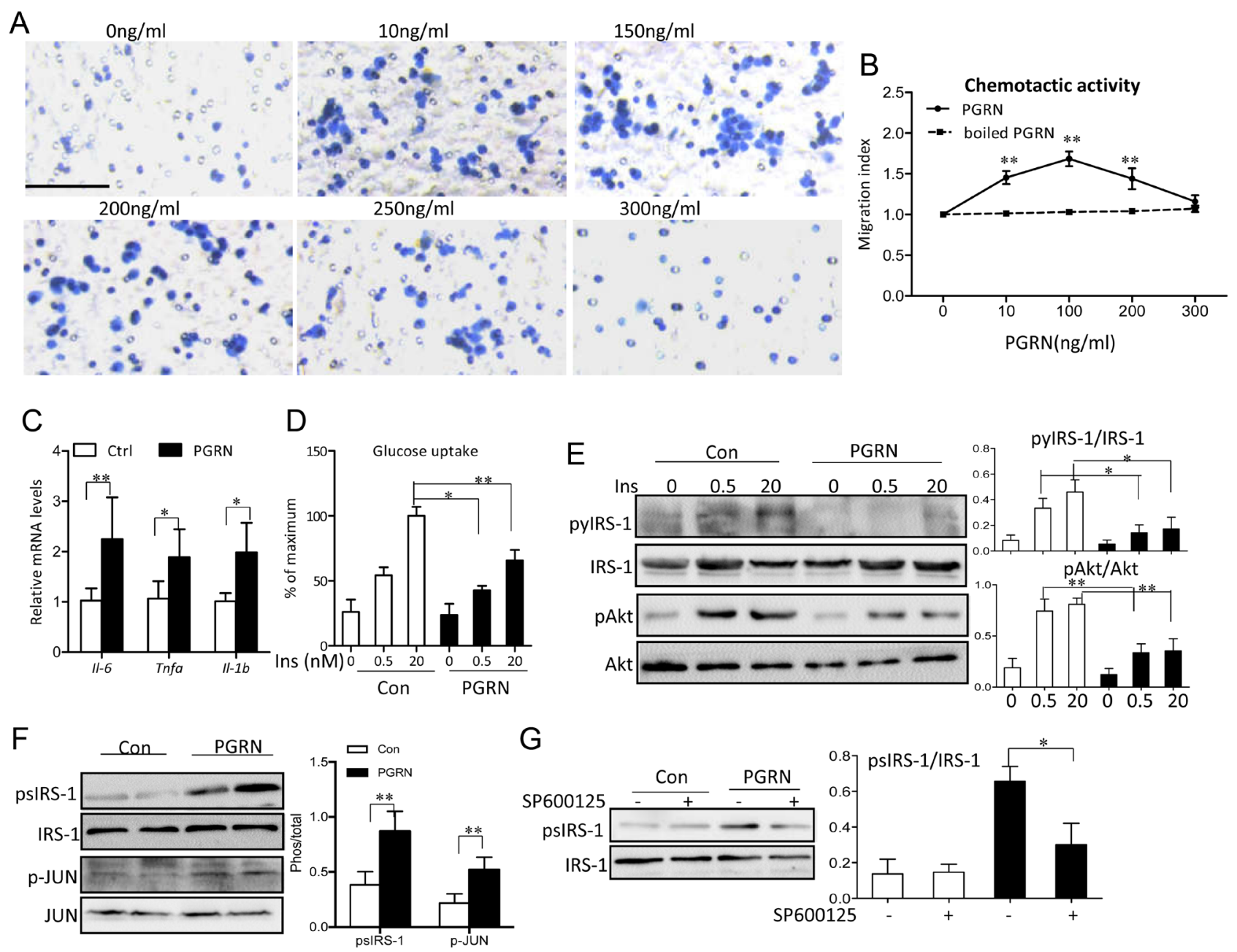

G

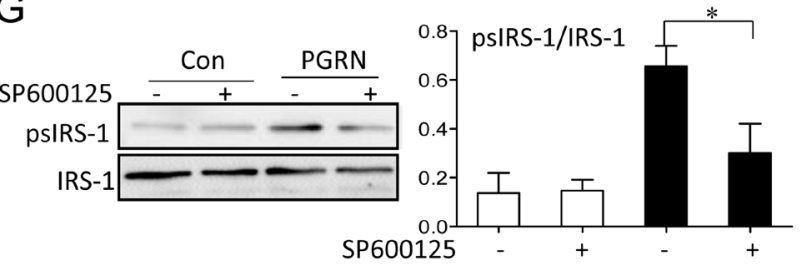

Figure 1

PGRN induces chemotactic activity and impairs insulin action in vitro. (A and B) Trans-well migration assay using Raw 264.7 cells. Scale bar: 100 um. (C) The effects of PGRN on inflammatory gene expression. (D) Insulin-stimulated glucose uptake in PGRN-treated cells. (E) Insulin signaling in PGRN-treated cells. Cells were stimulated with insulin for 15 min at indicated concentration, and then Western blotting was performed with the indicated antibodies. (F) PGRN increased inflammatory pathway. (G) Reduced IRS-1 serine phosphorylation by JNK inhibition in the presence of PGRN. The graph shows the means \pm S.D, from three independent experiments. ${ }^{*} P<0.05, * \star P<0.01$. A full colour version of this figure is available at https://doi.org/10.1530/ JME-19-0211. 
activation, whereas IRS-1 Serine307 phosphorylation promoted by PGRN was partly recovered by inhibition of JNK activity with SP600125 (Fig. 1G).

\section{PGRN knockdown repressed inflammatory gene expression and enhanced insulin action in vitro}

To further investigate the action of PGRN on adipose insulin signaling and inflammation, we next examined insulin receptor signaling and inflammatory factors expression in cellular models deficient in PGRN. Pgrn siRNA efficiency was validated by reduced PGRN protein measured by Western blotting (Fig. 2A). Since TNF- $\alpha$ is a major proinflammatory cytokine that can cause systemic inflammation and impaired insulin sensitivity, we then determined whether TNF- $\alpha$-induced effects could be rescued by PGRN knockdown. To accomplish this, we measured the effects of TNF- $\alpha$ in adipocytes that were pretreated with or without Pgrn siRNA. Figure 2B, C, D and $\mathrm{E}$ shows that TNF- $\alpha$ exposure led to a remarkable suppression of insulin responsiveness and an elevation of IL-1 $\beta$ and IL- 6 expression. However, all these changes could be partially rescued by PGRN knockdown, as validated by an increase in glucose uptake (Fig. 2B), IRS-1 tyrosine phosphorylation and AKT phosphorylation
(Fig. 2C), accompanied by a significant decrease in IRS- 1 serine phosphorylation, IL- $1 \beta$ and IL- 6 expression (Fig. 2C, D and E), with reduction in ERK phosphorylation and JNK activity (Fig. 2F).

\section{PGRN causes insulin resistance and induces inflammation and macrophage infiltration in AT}

To further explore if PGRN impairs insulin sensitivity and exerts an inflammatory activity in AT in vivo, we then administered PGRN intraperitoneally daily at the dosage of $1 \mu \mathrm{g} / \mathrm{g}$ body weight/d to wild type mice for 4 weeks. Consistent with our previous results, despite PGRN administration led to no significant changes in total body weight, fasting insulin level and blood glucose level (data not shown), insulin sensitivity assessed by ITT in mice treated with PGRN were slightly impaired (data not shown). Besides, insulin signaling was inhibited in AT of mice injected with PGRN, as shown by the attenuation of IRS- 1 tyrosine phosphorylation and AKT phosphorylation and increase in IRS-1 serine phosphorylation (Fig. 3A). Although we observed no significant changes in Adipoq, Ap2, and Pparg mRNA expression in AT between PGRN-treated mice and controls (Fig. 3B), several cytokines including TNF-
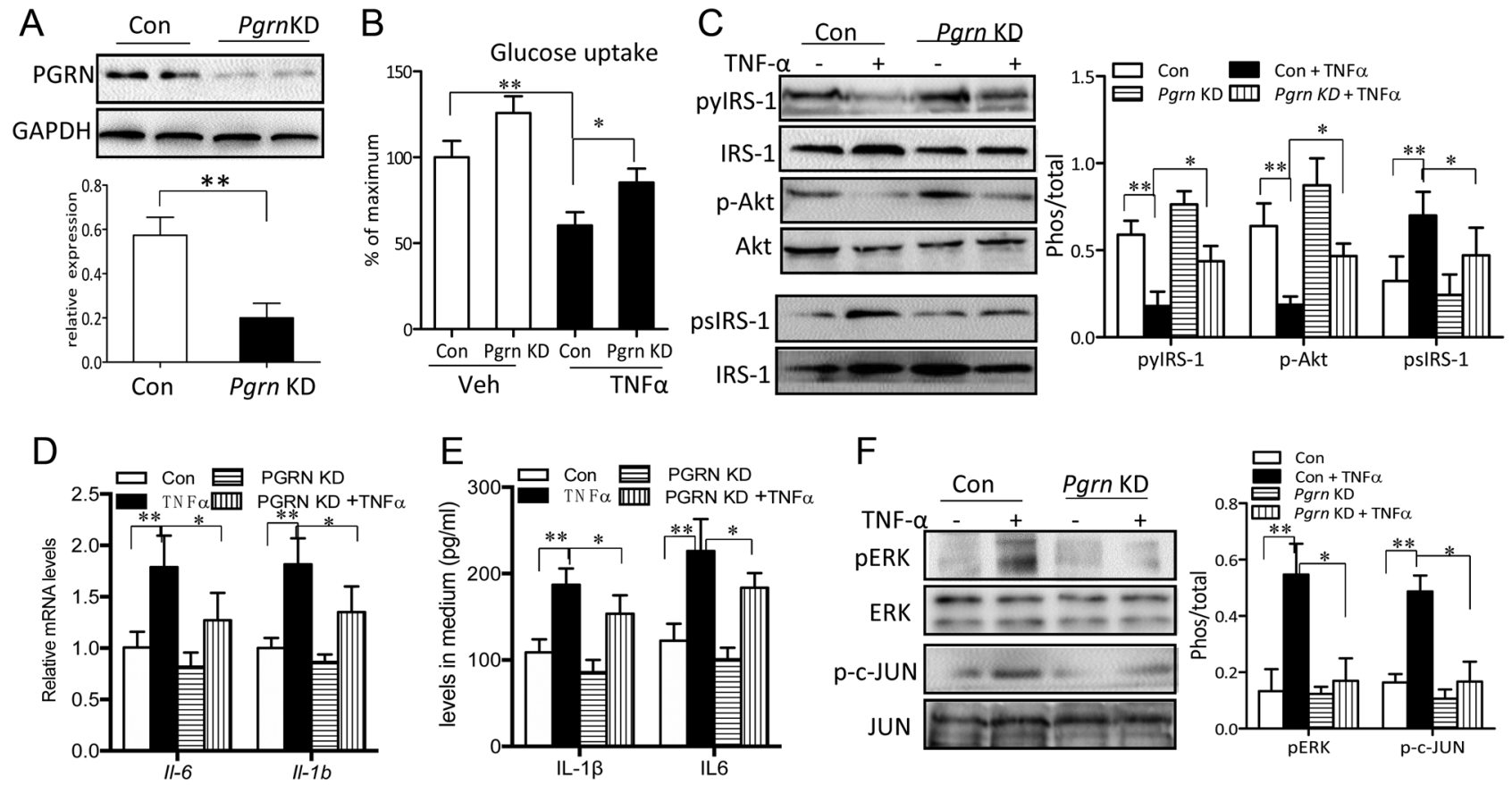

Figure 2

Knockdown of PGRN repressed proinflammatory gene expression and enhanced insulin action in vitro. (A) SiRNA against Pgrn decreased the expression of PGRN. (B) Knockdown of PGRN increased insulin-stimulated glucose uptake in adipocytes treated with or without TNF $\alpha$. Cells were stimulated with 20 $\mathrm{nM}$ insulin for $25 \mathrm{~min}$. (C) Insulin signaling pathway induced by TNF $\alpha$ treatment in PGRN knockdown cells. (D and E) mRNA expression of $/ /-1 b$ and $/ / 6$ (D) and medium levels of IL-1 $\beta$ and IL-6. (F) The effects of PGRN knockdown on TNF $\alpha$-induced inflammatory pathway. ${ }^{*} P<0.05$, $* \star P<0.01$. 
$\alpha$, IL-1 $\beta$, and IL- 6 were elevated in plasma or AT from PGRN-treated mice (Fig. 3B and C). Since production of cytokines in AT during an inflammatory response is generally accompanied by recruitment of macrophages, we hypothesized that some of these cytokines might also associate with increased macrophages infiltration. Indeed, WAT staining from mice treated with PGRN by hematoxylin and eosin revealed a cellular infiltration that was absent in controls, although fat pads weight and adipocyte diameter did not differ from control mice (Fig. 3D and data not shown). The immunohistological staining also suggests that $\mathrm{F} 4 / 80$ protein was increased in the fat tissue of mice treated with PGRN (Fig. 3E). As seen in Fig. 3F, PGRN treatment also led to an increase in mRNA expression for monocyte chemoattractant protein-1 (Mcp-1), hypoxia-inducible factor (Hif1a), and vascular endothelial growth factor A (Vegfa). This group of data suggests that inflammation is initiated and/or aggravated in the AT of PGRN-treated mice and then may contribute to the decreased insulin sensitivity.

\section{PGRN promotes NF-кB nuclear translocation and NF-кB dependent gene expression}

To explore the potential mechanisms underlining the effects of PGRN on insulin signaling and inflammation in obese AT, we assessed the phosphorylation and acetylation levels of NF- $\mathrm{kB}$, a known mediator in propagating obesityassociated AT inflammation. There is an increase in the phosphorylation of p65 in WAT of PGRN-treated mice compared with controls (Fig. 4A). By utilizing anti-acetyl-p65 antibody, which recognizes NF-kB p65 acetylated at lysine 310, we also observed a significant increase in p65 acetylation (Fig. 4A), which plays a key

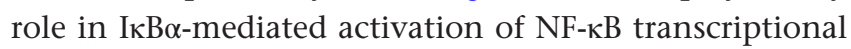
activity. Likewise, an increase in p65 phosphorylation, p65 nuclear translocation, and p65 acetylation were observed in 3T3L1 adipocytes (Fig. 4B and C).

In view of the results presented above, we next asked whether, conversely, a significant inhibition of NF- $\mathrm{kB}$ activity would rescue the glucose intolerance and proinflammatory gene expression induced by
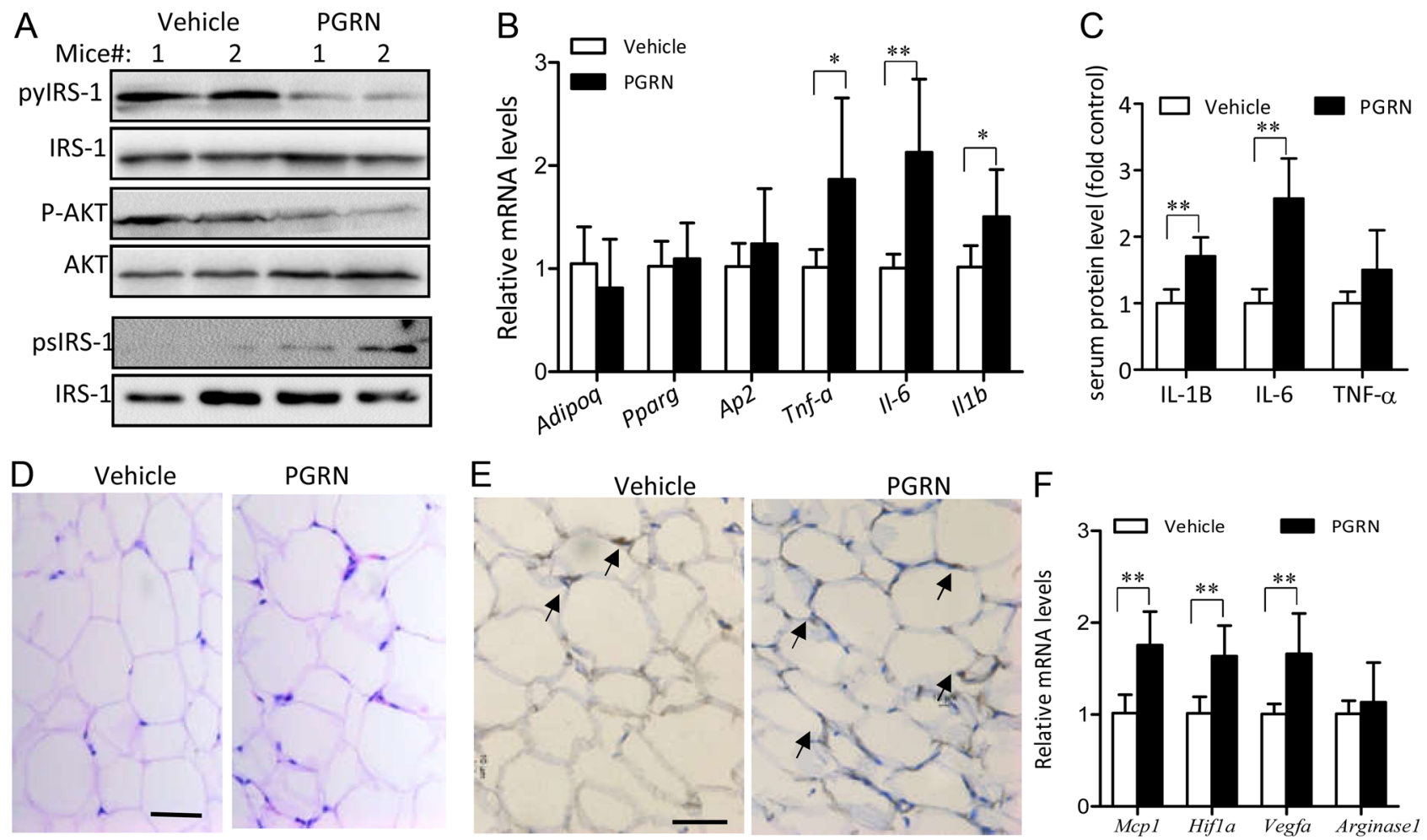

Figure 3

PGRN causes insulin resistance and adipose tissue dysfunction in vivo. (A) Insulin sensitivity in epididymal fat of PGRN-treated mice. (B) mRNA expression of Adiponectin (Adipoq), Pparg, ap2 and pro-inflammatory genes $/ 1-1 b, \| 6$, Tnfa in epididymal fat. (C) Serum levels of TNF $\alpha$, IL-1 $\beta$ and IL-6 in vivo. (D) H\&E staining of epididymal fat. (E) Immunostaining of F4/80 in visceral fat. (F) mRNA expression of Mcp-1, Hif1a, Vegfa and Arginase1 in visceral fat. Scale bar: $50 \mu \mathrm{m} . * P<0.05, * * P<0.01$. A full colour version of this figure is available at https://doi.org/10.1530/JME-19-0211. 


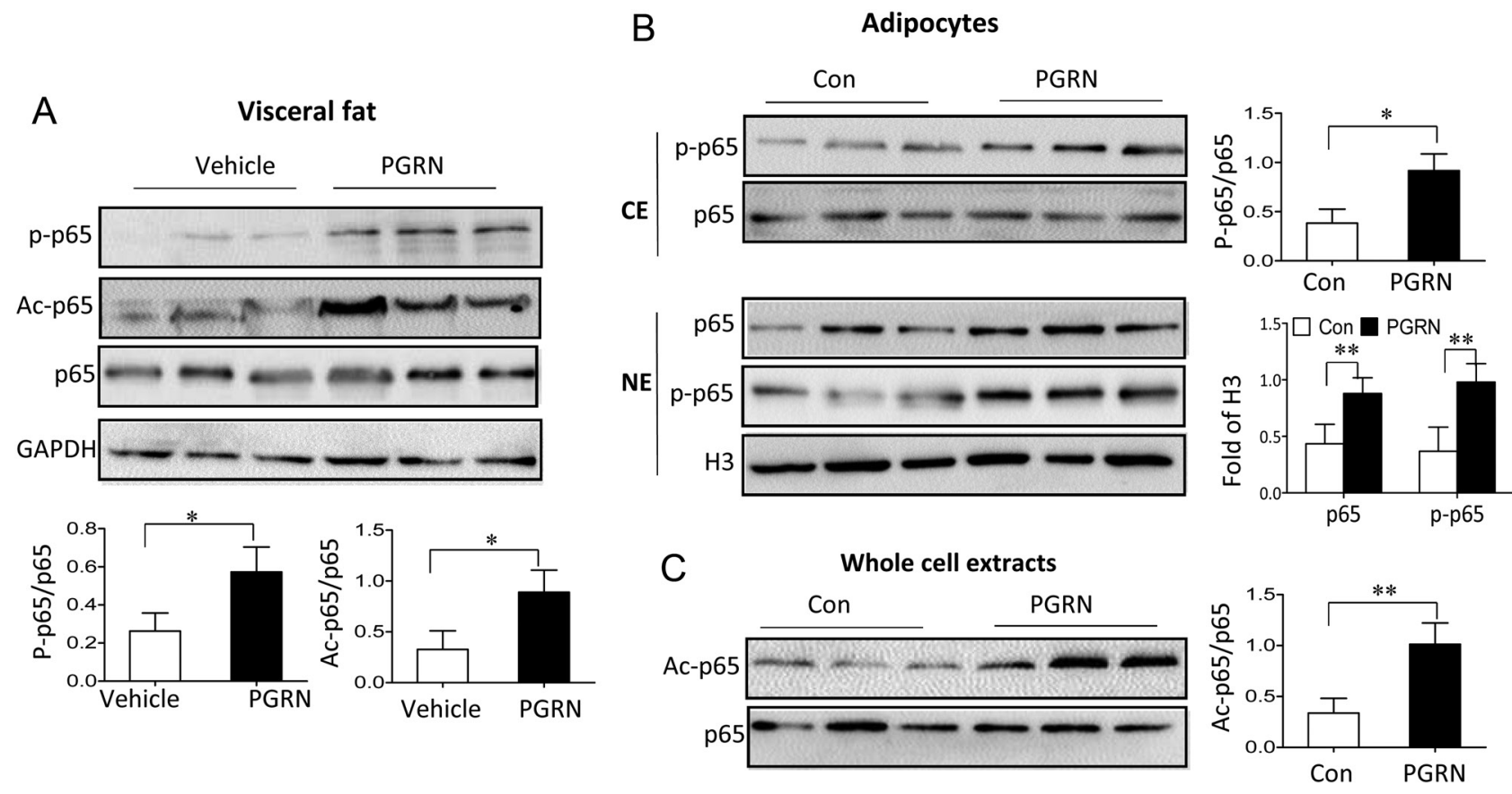

Figure 4

PGRN exposure led to NF-kB p65 activation. (A) Phosphorylation and acetylation of NF-kB p65 in epididymal fat. (B) Effects of PGRN on phosphorylation and translocalization of NF-kB p65 in adipocytes. Cytoplasmic and neutral extracts were prepared. (C) Effects of PGRN on acetylation of NF-kB p65 in adipocytes. Whole cell extracts were prepared. $* P<0.05, * \star P<0.01$.

PGRN treatment. $N f-\kappa b$ siRNA efficiency was verified by the reduced NF-kB p65 expression (Fig. 5A). Of note, blockade of NF- $\mathrm{B}$ activity by the addition of PDTC in the culture medium or by transfection with $N f-\kappa b$ siRNA in cells nullified the impairment of PGRN on insulin signaling, as shown by decrease in serine phosphorylation of IRS-1, and elevation in tyrosine phosphorylation of IRS-1 and Akt phosphorylation (Fig. 5B and C), increase in glucose uptake (Fig. 5D). Meanwhile, the expression of $I l-1 b$, Il-6, and Tnfa mRNA as well as IL-1 $\beta$ and IL-6 secretion in media induced by PGRN were also partially rescued by suppression of NF-кB activity (Fig. 5E and F).

\section{SIRT1 is required for PGRN-mediated effects on adipose inflammation and insulin sensitivity}

Acetylation levels of NF- $\mathrm{B}$ are under the tight control of SIRT1 that functions in AT to protect from inflammation and obesity. Thus, we were not sure whether the inflammation and insulin resistance observed in this study is related to a change in the SIRT1 expression in AT of PGRN-treated mice. To address this question, we first observed a reduction of SIRT1 protein in the fat tissue of PGRN-treated mice by immunohistology staining and Western blotting (Fig. 6A and B). Accordingly, TNF- $\alpha$-induced inhibition of SIRT1 expression was also partly rescued by PGRN knockdown (Fig. 6C). Next we examined the effects of SIRT1 overexpression in 3T3L1 adipocytes (Fig. 6D). Consistent with an increase in PGRNinhibited glucose uptake (Fig. 6E), overexpression of SIRT1 also significantly rescued tyrosine phosphorylation of IRS-1 and Akt phosphorylation impaired by PGRN treatment in adipocytes (Fig. 6F). Furthermore, we also found a reduction of JNK activity with a corresponding decrease in serine phosphorylation of IRS-1, and NF- $\mathrm{BB}$ acetylation induced by PGRN treatment in SIRT1overexpressing adipocytes (Fig. 6G), as well as decreased expression of IL-1 $\beta$, IL- 6 , and TNF- $\alpha$ (Fig. $6 \mathrm{H}$ and I).

On the basis of the ability of SIRT1 to repress inflammatory components in 3T3-L1 adipocytes, we next sought to determine whether a highly selectively SIRT1 activator, SRT1720, could produce similar effects. SIRT1 activation also led to a decrease in the ratio of acetylated p65 to total p65, and a recovery in PGRN-induced insulin signaling impairments and proinflammatory gene expression, although no change in SIRT1 protein expression was observed (data not shown). EX527, a known specific SIRT1 inhibitor, could also significantly abolished the effects of PGRN knockdown in adipocytes exposed to TNF- $\alpha$ (data not shown), as shown by the increased p65 acetylation and IRS-1 serine phosphorylation, 
A

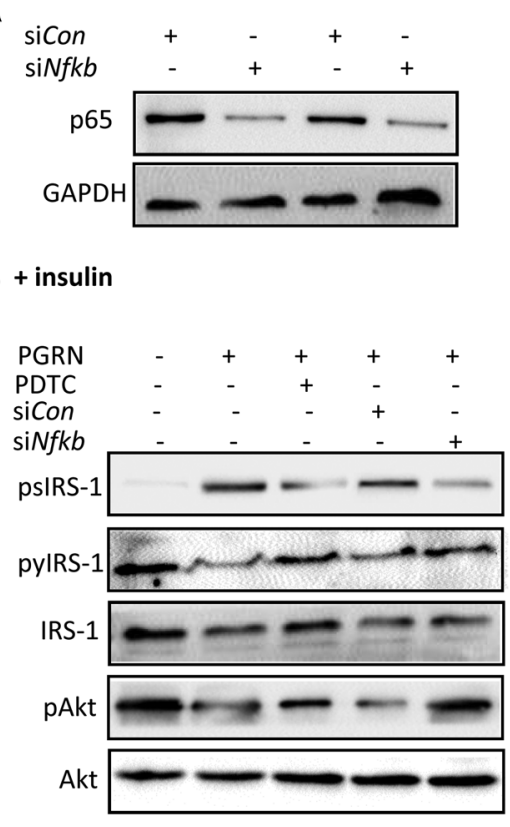

C

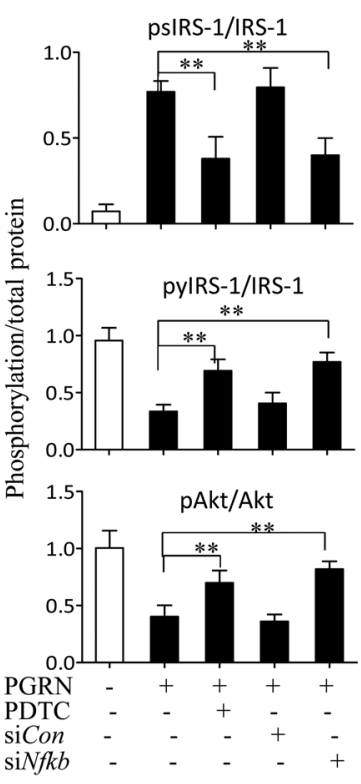

$D+$ insulin

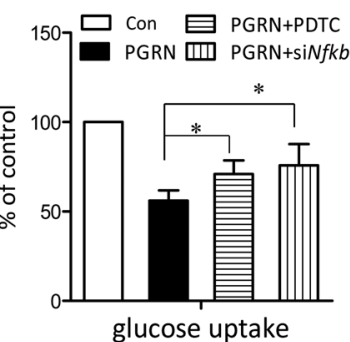

glucose uptake
F
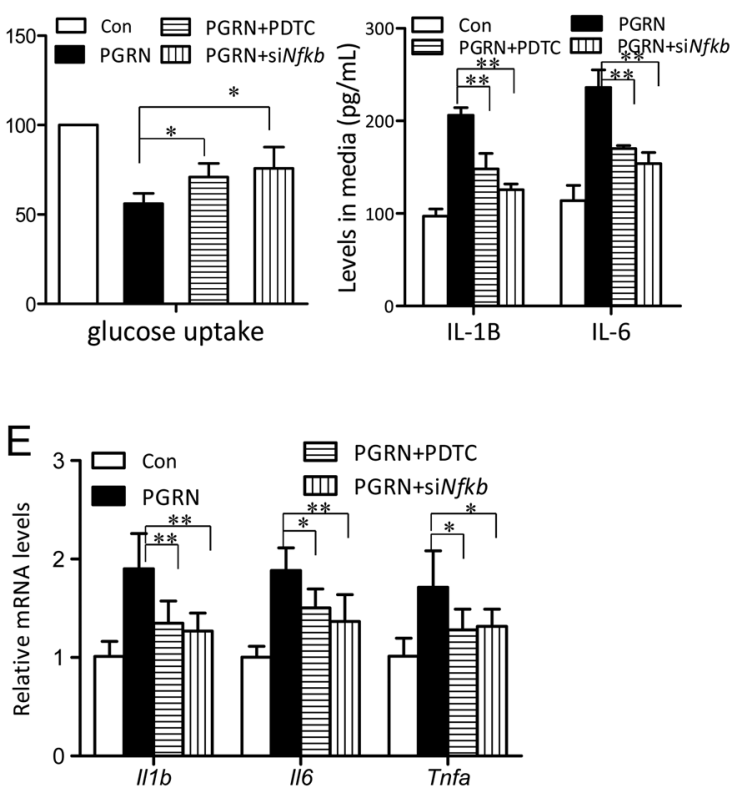

Figure 5

Effects of NF-kB p65 inhibition on impaired insulin sensitivity and increased inflammatory response induced by PGRN. (A) Validation of PGRN knockdown

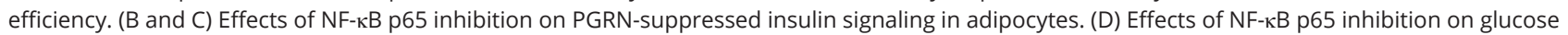
uptake impaired by PGRN. mRNA expression of $/ I-1 b, \| / 6$, Tnfa (E) and medium levels of IL-1 $\beta$ and IL-6 (F). *P<0.05, **P<0.01.

and decreased IRS-1 tyrosine phosphorylation. Meanwhile, EX527 treatment with PGRN knockdown also increased $I l-6$, and $I l-1 b$ expression (data not shown). These in vitro findings suggest that preventing the normal decrease in SIRT1 activation caused by PGRN treatment is sufficient to protect from PGRN-induced proinflammatory gene expression and insulin signaling impairment via deacetylation of NF-кB.

\section{Discussion}

The major findings of this study relate to the consequences of increased PGRN expression on AT insulin sensitivity and inflammation by controlling the gain of proinflammatory transcription. We demonstrated that PGRN expression were increased by HFD in AT and PGRN administration led to inflammatory pathway activation with increased inflammatory gene expression, accompanied by decreased insulin-stimulated glucose uptake, impaired insulin signaling, and a state of cellular insulin resistance. These effects were partially nullified by blockade of NF-кB or overexpression of SIRT1, which produced antiinflammatory impacts and protected cells from PGRN induced insulin resistance. These data suggest that the upregulation of PGRN may be a key feature involved in obesity-associated AT inflammation and insulin resistance.
Increasing evidence shows that chronic inflammation, particularly in liver and AT, is an important pathophysiologic cause of decreased systemic insulin sensitivity (Shoelson et al. 2006). In fact, AT expansion during obesity accompanies with macrophages infiltration, which is a dominate source of pro-inflammatory cytokines such as MCP-1 and IL6 and provides a potential link between inflammation and insulin resistance (Sun et al. 2011, Martinez-Santibanez \& Lumeng 2014). PGRN caught our attention because it is an important molecule in inflammatory response and could therefore be involved in chronic subclinical inflammation associated with insulin resistance in obesity. This hypothesis is supported by our observation that PGRN levels were increased in the insulin resistant state and PGRN treatment induced impaired insulin signaling, macrophages infiltration, and the expression of IL-1 $\beta$, TNF- $\alpha$, and IL- 6 . These findings were consistent with previous work demonstrating that PGRN is a major adipokine of mediated HFD-induced insulin resistance by inducing upregulation of IL-6 expression (Jian et al. 2013). Accordingly, we also found PGRN could function as a chemotactic protein for Raw 264.7 cells. The extent of in vitro PGRN-mediated chemotaxis is similar to that of MCP-1. Moreover, multivariable linear regression analyses revealed CRP levels as the strongest independent predictor 
A

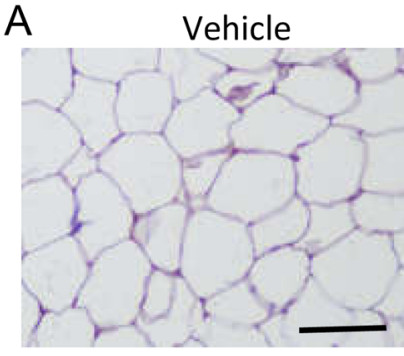

D

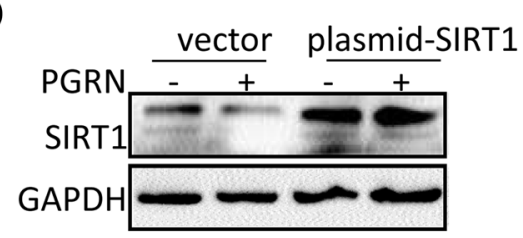

E

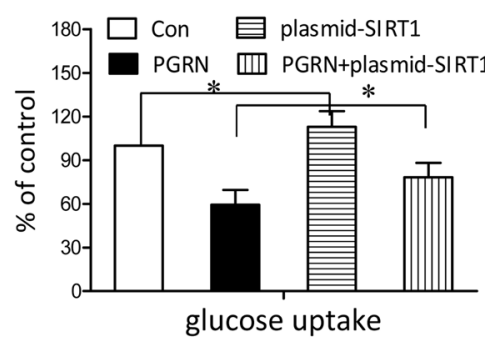

G

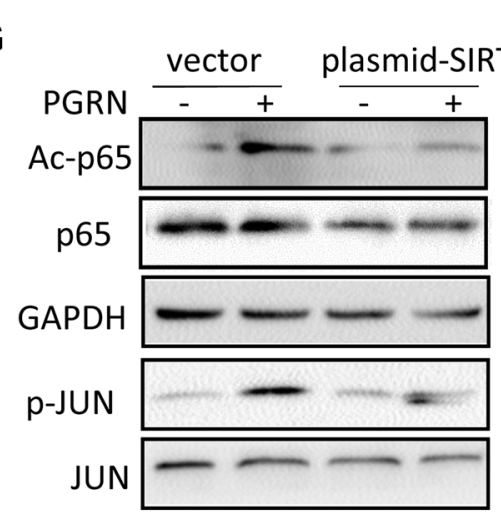

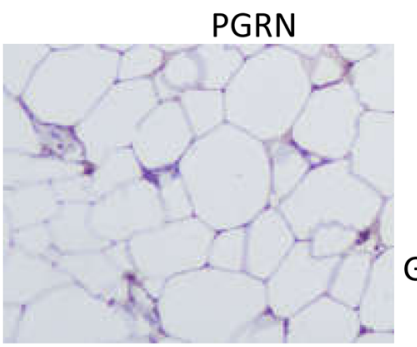

B

C

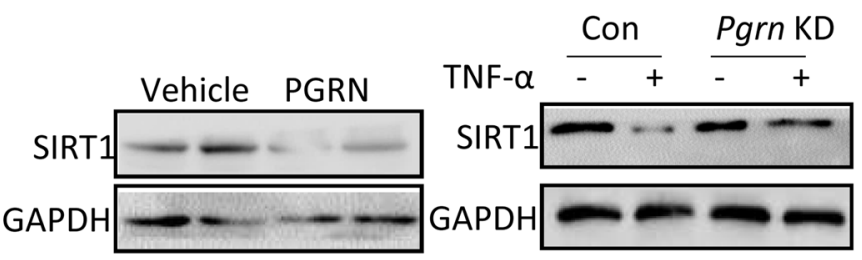

F

PGRN $\frac{\text { vector plasmid -SIRT1 }}{-} \frac{+}{+}$
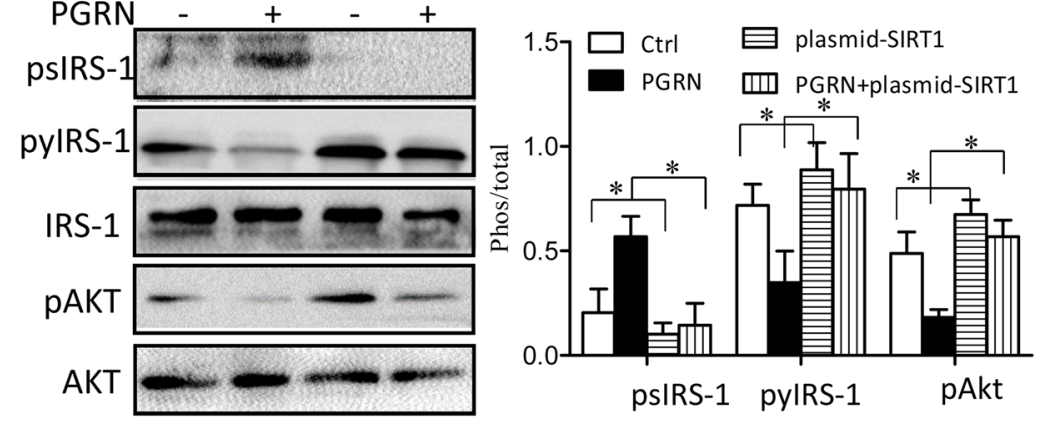

$\mathrm{H}$
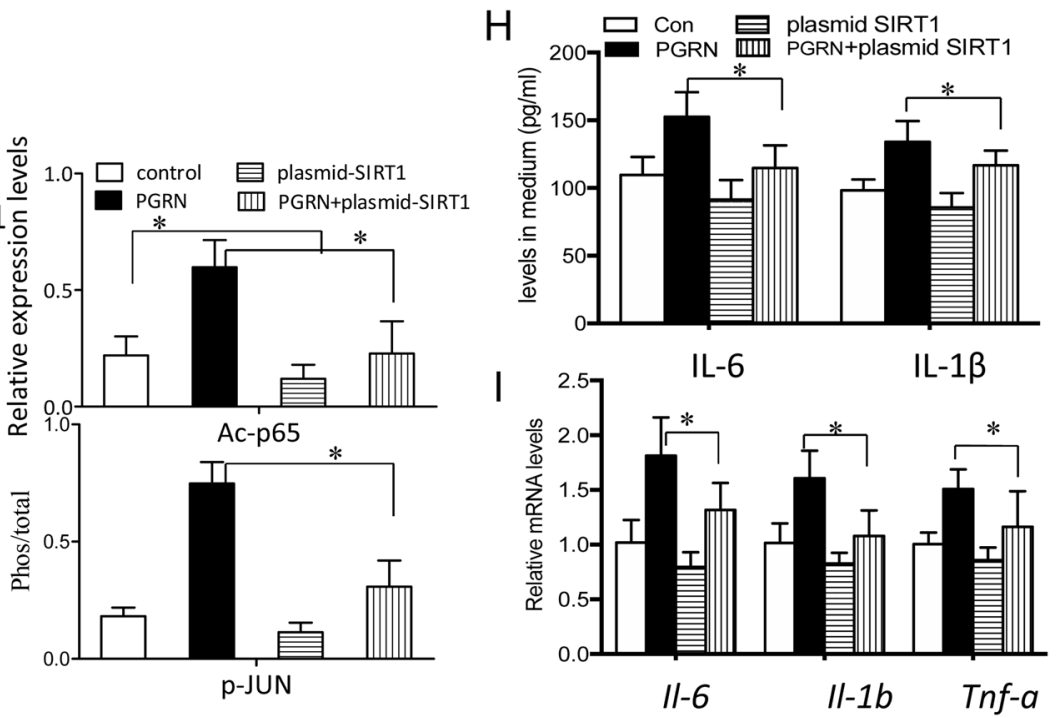

Figure 6

Effects of SIRT1 on impaired insulin sensitivity and increased inflammatory response induced by PGRN. (A) Immunostaining of SIRT1 expression in epididymal fat tissue. (B) SIRT1 protein expression in visceral fat tissue. (C) The effects of PGRN knockdown on TNF $\alpha$-induced SIRT1 expression. (D) Validation of SIRT1 overexpression in adipocytes. (E and F) Effects of SIRT1 overexpression on PGRN-inhibited insulin signaling and glucose uptake. (G) Effects of SIRT1 overexpression on acetylation of NF-KB p65 and JNK activation induced by PGRN. The medium levels of IL-1 $\beta$ and IL-6 (H) and mRNA expression of $/ 1-1 b, \| / 6$, Tnfa (I). $* P<0.05, * * P<0.01$. A full colour version of this figure is available at https://doi.org/10.1530/JME-19-0211.

of circulating PGRN, which positively correlated with macrophage infiltration in omental AT. Thus, obesityassociated PGRN upregulation in AT seems to aggravate inflammation to mediate insulin resistance.

Besides its contribution to the development of insulin resistance in HFD-induced diabetes, PGRN demonstrates proinflammatory functions in NAFLD (Yilmaz et al. 2011). However, the role of PGRN during inflammation may be quite controversial. Indeed, PGRN exerts its anti-inflammatory activity through inhibition of chemokine release from macrophages and induction of Treg differentiation and IL-10 expression. In addition, the protective role of PGRN has also been demonstrated in neuro-injury, osteoarthritis, psoriasis, and inflammatory bowel disease (Tang et al. 2011, Jian et al. 2018). Unexpectedly, when AAV9-mediated PGRN 
overexpression was delivered to lateral ventricle to treat frontotemporal dementia, selective PGRN secretion also resulted in $\mathrm{T}$ cell infiltration, as well as ependymal hypertrophy (Amado et al. 2019). Likewise, Pgrn-deficient mice were resistant to autoimmune encephalomyelitis, and influenza virus-induced lung injury and mortality (Luo et al. 2019, Schmitz et al. 2019), suggesting the dichotomy of PGRN-mediated inflammation. In line with our results, Matsubara et al. also demonstrated that infiltration of mac-3 positive inflammatory cells was significantly less in Grn-/- mice than that in WT mice under HFD condition (Matsubara et al. 2012). Some studies reported inhibition of neutrophil elastase activity suppressed PGRN cleavage and the increase in proinflammatory cytokines after cerebral ischemia (Horinokita et al. 2019). Thus, it remains to be explored whether these controversy in PGRN-mediated inflammation was caused by the neutrophil elastase activity in various diseases. Also, the function of PGRN might quite be diverse in AT of obesity compared with its role in other tissues and that requires further comprehensive study to elucidate the detailed mechanisms.

PGRN, as a growth factor, promotes cell proliferation and is crucial to the development and generation of fastgrowing epithelial and endothelial cells, and its expression leads to promotion of blood vessel development and vascular remodeling (Yang et al. 2015). Another study reported that PGRN was induced as a stress-response factor subjected to hypoxia in fibroblasts (Guerra et al. 2007), and there is evidence from several studies that obesity generates a hypoxic environment in AT (Sun et al. 2011, Martinez-Santibanez \& Lumeng 2014). This hypoxia may be a means by which adipocyte hypertrophy generates PGRN upregulation in our study. In addition, adipose macrophages stimulate angiogenesis through production of cytokines (Martinez-Santibanez \& Lumeng 2014). Thus, it is plausible that PGRN might also regulate AT function through angiogenesis in obesity. In light of this, we observed that there were significant increases in proangiogenic growth factors, including Hif- $1 \alpha$ and Vegfa expression induced by PGRN in the AT. However, the relationship among angiogenesis, inflammation, and insulin resistance in AT during obesity remains uncertain. Some studies reported AT from obese patients showed a lower angiogenic capacity that was associated with insulin resistance (Spencer et al. 2011), while others reported pharmacological inhibition of adipose angiogenesis in obese animals prevented obesity development and insulin resistance (Luo et al. 2016). Actually, angiogenesis is required for adipocyte expansion as well as for maintenance of AT function (Cao 2010). Thus, it remains unclear whether modulation of angiogenesis by PGRN contributes to metabolic insulin resistance. Overall, although PGRN may drive new vessel formation in some conditions, in obesity it may primarily serve as a proinflammatory signal and a promoter of abnormal metabolic profiles with impaired glucose tolerance.

However, as PGRN is administered systemically in this study, the observations might not exclusively be attributed to PGRN itself, since PGRN is composed of 7.5 repeats of a cysteine-rich motif. Proteolytic cleavage of this precursor protein by extracellular proteases gives rise to smaller peptide fragments termed granulins (GRNs) or epithelins. As above mentioned, the normal function of PGRN is complex, with intact PGRN having anti-inflammatory properties in neuroinflammation and arthritis or proinflammatory properties in obesity and insulin-resistant diabetes mellitus, whereas GRNs has been always shown to promote inflammatory response (Park et al. 2011). It is therefore unclear at this point whether GRNs derived by proteolysis of PGRN is implicated in the inhibition of insulin sensitivity and promotion of systemic inflammation in the present study. Our previous preliminary results showed that elastase-digested PGRN had little effects on insulin signaling and autophagy activity in cultured hepatocytes (Liu et al. 2015). However, since GRNs range in size from 6 to $25 \mathrm{kDa}$, so far it is difficult to measure serum GRNs or to investigate the function of GRNs on AT in vivo (Tanaka et al. 2012).

Though PGRN has been reported to involve in the pathogenesis of insulin resistance through IL-6, the mechanisms of PGRN inductive effects on adipocyte inflammatory pathway have not been addressed. In this regard, it has been shown that PGRN physically interacts with the p65 subunit of NF-кB that seems to be the earliest inflammatory pathway altered at the transcriptional level in obesity-associated AT (Wu et al. 2011, Peng et al. 2018). Therefore, we hypothesized that, within adipocytes, PGRN exerts inflammatory effects possibly through NF-kB, which, in turn, contributes to insulin resistance. Consistent with this idea we showed that PGRN was a potent promoter of NF- $\mathrm{kB}$ activation corresponded with the sequential enhancement of p65 phosphorylation, p65 nuclear translocation, p65 acetylation, and NF- $\mathrm{KB}$ binding to target gene promoters. We also show that the impacts of PGRN on insulin signaling and inflammatory cytokine expression were partly abolished by blockade of NF-kB. Evidence for this concept can also be seen from our previous work 
on adipocytes, which showed a critical role of PGRN in triggering the unfolded protein response generally interacted with NF-кB signaling (Yamazaki et al. 2009). For instance, PERK signaling activates NF- $\kappa B$, while translation of $\mathrm{I} \kappa \mathrm{B} \alpha$, the main negative regulator of $\mathrm{NF}-\kappa \mathrm{B}$, is known to be inhibited by phosphorylation of eIF $2 \alpha$. Thus, NF- $\kappa \mathrm{B}$ activation seems a cause of PGRN-induced AT inflammation, contributing to decreased insulin sensitivity.

Several recent studies have implicated the regulation of SIRT1 in inflammatory responses, which could modulate insulin signaling (Yoshizaki et al. 2009). In human s.c. fat SIRT1 expression is inversely related to AT macrophage infiltration. Of note, one of the targets for SIRT1 deacetylation is NF-кB (Han et al. 2017). These data are consistent with our results showing that SIRT1 overexpression in 3T3L1 adipocytes decreased NF- $\mathrm{B}$ acetylation and inhibited NF-кB-mediated inflammatory gene expression. This raised the question of whether SIRT1 could also mediate repressive effects of PGRN on insulin sensitivity via NF-кB. Our findings showed that PGRN caused SIRT1 down-regulation and SIRT1 overexpression prevents the further worsening of insulin resistance induced by PGRN, similar with NF-кB knockdown. These data suggest that the increased inflammatory responses and decreased insulin action induced by PGRN are partly via SIRT1/NF- $\mathrm{B}$ signaling.

In conclusion, our findings demonstrate the effects of PGRN on inflammation in adipose insulin resistance. Glucose tolerance and insulin sensitivity were decreased in the PGRN-treated mice, along with an increase in macrophages-derived inflammation, whereas blockade of NF- $\mathrm{B}$ or SIRT1 overexpression attenuated the detrimental effects of PGRN. These results suggest that PGRN impacts on inflammation in adipose insulin resistance partly via SIRT1-NF- $\mathrm{B}$ signaling and modulating of PGRN secretion/ action is probably a promising therapeutic approach applied to metabolic disorders.

\section{Declaration of interest}

The authors declare that there is no conflict of interest that could be perceived as prejudicing the impartiality of the research reported.

\section{Funding}

This work was supported by grants from the Postdoctoral Science Foundation of China (grant number 2016M592803); and the National Natural Science Foundation of China (grant numbers 81600621, 81670734, 81672221), and National Key Research and Development Program of China Grant (2018YFC1002803).

\section{References}

Alissa EM, Sutaih RH, Kamfar HZ, Alagha AE \& Marzouki ZM 2017 Serum progranulin levels in relation to insulin resistance in childhood obesity. Journal of Pediatric Endocrinology and Metabolism 30 1251-1256. (https://doi.org/10.1515/jpem-2017-0321)

Amado DA, Rieders JM, Diatta F, Hernandez-Con P, Singer A, Mak JT, Zhang J, Lancaster E, Davidson BL \& Chen-Plotkin AS 2019 AAVmediated progranulin delivery to a mouse model of progranulin deficiency causes T cell-mediated toxicity. Molecular Therapy 27 465-478. (https://doi.org/10.1016/j.ymthe.2018.11.013)

Arechavaleta-Velasco F, Perez-Juarez CE, Gerton GL \& Diaz-Cueto L 2017 Progranulin and its biological effects in cancer. Medical Oncology 34 194. (https://doi.org/10.1007/s12032-017-1054-7)

Cao YH 2010 Adipose tissue angiogenesis as a therapeutic target for obesity and metabolic diseases. Nature Reviews: Drug Discovery 9 107-115. (https://doi.org/10.1038/nrd3055)

Cenik B, Sephton CF, Kutluk Cenik B, Herz J \& Yu G 2012 Progranulin: a proteolytically processed protein at the crossroads of inflammation and neurodegeneration. Journal of Biological Chemistry $\mathbf{2 8 7}$ 32298-32306. (https://doi.org/10.1074/jbc.R112.399170)

Cerezo LA, Kuklova M, Hulejova H, Vernerova Z, Kasprikova N, Veigl D, Pavelka K, Vencovsky J \& Senolt L 2015 Progranulin is associated with disease activity in patients with rheumatoid arthritis. Mediators of Inflammation 2015 740357. (https://doi. org/10.1155/2015/740357)

Chitramuthu BP, Bennett HPJ \& Bateman A 2017 Progranulin: a new avenue towards the understanding and treatment of neurodegenerative disease. Brain 140 3081-3104. (https://doi. org/10.1093/brain/awx198)

Frampton G, Ueno Y, Quinn M, Mcmillin M, Pae HY, Galindo C, LeyvaIllades D \& Demorrow S 2012 The novel growth factor, progranulin, stimulates mouse cholangiocyte proliferation via sirtuin-1-mediated inactivation of FOXO1. American Journal of Physiology: Gastrointestinal and Liver Physiology 303 G1202-G1211. (https://doi.org/10.1152/ ajpgi.00104.2012)

Gillum MP, Kotas ME, Erion DM, Kursawe R, Chatterjee P, Nead KT, Muise ES, Hsiao JJ, Frederick DW, Yonemitsu S, et al. 2011 SirT1 regulates adipose tissue inflammation. Diabetes $603235-3245$. (https://doi.org/10.2337/db11-0616)

Guerra RR, Kriazhev L, Hernandez-Blazquez FJ \& Bateman A 2007 Progranulin is a stress-response factor in fibroblasts subjected to hypoxia and acidosis. Growth Factors 25 280-285. (https://doi. org/10.1080/08977190701781222)

Han Y, Luo H, Wang H, Cai J \& Zhang Y 2017 SIRT1 induces resistance to apoptosis in human granulosa cells by activating the ERK pathway and inhibiting NF-kappaB signaling with antiinflammatory functions. Apoptosis 22 1260-1272. (https://doi. org/10.1007/s10495-017-1386-y)

He ZH, Ong CHP, Halper J \& Bateman A 2003 Progranulin is a mediator of the wound response. Nature Medicine 9 225-229. (https://doi. org/10.1038/nm816)

Horinokita I, Hayashi H, Oteki R, Mizumura R, Yamaguchi T, Usui A, Yuan B \& Takagi N 2019 Involvement of progranulin and granulin expression in inflammatory responses after cerebral ischemia. International Journal of Molecular Sciences 20 5210. (https://doi. org/10.3390/ijms20205210)

Hossein-Nezhad A, Mirzaei K, Ansar H, Emam-Gholipour S, Tootee A \& Keshavarz SA 2012 Obesity, inflammation and resting energy expenditure: possible mechanism of progranulin in this pathway. Minerva Endocrinologica 37 255-266. (https://doi.org/10.1530/JOE11-0461e)

Jian J, Konopka J \& Liu C 2013 Insights into the role of progranulin in immunity, infection, and inflammation. Journal of Leukocyte Biology 93 199-208. (https://doi.org/10.1189/jlb.0812429) 
Jian J, Li G, Hettinghouse A \& Liu C 2018 Progranulin: a key player in autoimmune diseases. Cytokine 101 48-55. (https://doi.org/10.1016/j. cyto.2016.08.007)

Li HX, Zhou B, Liu JL, Li F, Li YL, Kang X, Sun HZ \& Wu SF 2015 Administration of progranulin (PGRN) triggers ER stress and impairs insulin sensitivity via PERK-eIF2alpha-dependent manner. Cell Cycle 14 1893-1907. (https://doi.org/10.1080/15384101.2015.1041686)

Liu JL, Li HX, Zhou B, Xu L, Kang XM, Yang W, Wu SF \& Sun HZ 2015 PGRN induces impaired insulin sensitivity and defective autophagy in hepatic insulin resistance. Molecular Endocrinology 29 528-541. (https://doi.org/10.1210/me.2014-1266)

Luo X, Jia R, Yao Q, Xu Y, Luo Z, Luo X \& Wang N 2016 Docosahexaenoic acid attenuates adipose tissue angiogenesis and insulin resistance in high fat diet-fed middle-aged mice via a sirt1dependent mechanism. Molecular Nutrition and Food Research 60 871-885. (https://doi.org/10.1002/mnfr.201500714)

Luo Q, Yan X, Tu H, Yin Y \& Cao J 2019 Progranulin aggravates pulmonary immunopathology during influenza virus infection. Thorax 74 305-308. (https://doi.org/10.1136/thoraxjnl-2018-211916)

Ma Y, Matsuwaki T, Yamanouchi K \& Nishihara M 2017 Involvement of progranulin in modulating neuroinflammatory responses but not neurogenesis in the hippocampus of aged mice. Experimental Gerontology 95 1-8. (https://doi.org/10.1016/j.exger.2017.05.003)

Martens LH, Zhang J, Barmada SJ, Zhou P, Kamiya S, Sun B, min SW, Gan L, Finkbeiner S, Huang EJ, et al. 2012 Progranulin deficiency promotes neuroinflammation and neuron loss following toxininduced injury. Journal of Clinical Investigation 122 3955-3959. (https://doi.org/10.1172/JCI63113)

Martinez-Santibanez G \& Lumeng CN 2014 Macrophages and the regulation of adipose tissue remodeling. Annual Review of Nutrition 34 57-76. (https://doi.org/10.1146/annurev-nutr-071812-161113)

Matsubara T, Mita A, Minami K, Hosooka T, Kitazawa S, Takahashi K, Tamori Y, Yokoi N, Watanabe M, Matsuo E, et al. 2012 PGRN is a key adipokine mediating high fat diet-induced insulin resistance and obesity through IL-6 in adipose tissue. Cell Metabolism 15 38-50. (https://doi.org/10.1016/j.cmet.2011.12.002)

Park B, Buti L, Lee S, Matsuwaki T, Spooner E, Brinkmann MM, Nishihara M \& Ploegh HL 2011 Granulin is a soluble cofactor for toll-like receptor 9 signaling. Immunity 34 505-513. (https://doi. org/10.1016/j.immuni.2011.01.018)

Peng J, Zhou Y, Deng Z, Zhang H, Wu Y, Song T, Yang Y, Wei H \& Peng J 2018 miR-221 negatively regulates inflammation and insulin sensitivity in white adipose tissue by repression of sirtuin-1 (SIRT1). Journal of Cellular Biochemistry 119 6418-6428. (https://doi. org/10.1002/jcb.26589)

Schmid A, Hochberg A, Kreiss AF, Gehl J, Patz M, Thomalla M, Hanses F, Karrasch T \& Schaffler A 2019 Role of progranulin in adipose tissue innate immunity. Cytokine 125 154796. (https://doi.org/10.1016/j. cyto.2019.154796)

Schmitz K, Wilken-Schmitz A, Vasic V, Brunkhorst R, Schmidt M \& Tegeder I 2019 Progranulin deficiency confers resistance to autoimmune encephalomyelitis in mice. Cellular and Molecular Immunology Epub. (https://doi.org/10.1038/s41423-019-0274-5)

Shoelson SE, Lee J \& Goldfine AB 2006 Inflammation and insulin resistance. Journal of Clinical Investigation 116 1793-1801. (https:// doi.org/10.1172/JCI29069)

Spencer M, Unal R, Zhu B, Rasouli N, Mcgehee RE, Peterson CA \& Kern PA 2011 Adipose tissue extracellular matrix and vascular abnormalities in obesity and insulin resistance. Journal of Clinical Endocrinology and Metabolism 96 E1990-E1998. (https://doi.org/10.1210/jc.2011-1567)
Sun K, Kusminski CM \& Scherer PE 2011 Adipose tissue remodeling and obesity. Journal of Clinical Investigation 121 2094-2101. (https://doi. org/10.1172/JCI45887)

Tanaka A, Tsukamoto H, Mitoma H, Kiyohara C, Ueda N, Ayano M, Ohta S, Inoue Y, Arinobu Y, Niiro H, et al. 2012 Serum progranulin levels are elevated in patients with systemic lupus erythematosus, reflecting disease activity. Arthritis Research and Therapy 14 R244. (https://doi.org/10.1186/ar4087)

Tang W, Lu Y, Tian QY, Zhang Y, Guo FJ, Liu GY, Syed NM, Lai Y, Lin EA, Kong L, et al. 2011 The growth factor progranulin binds to TNF receptors and is therapeutic against inflammatory arthritis in mice. Science 332 478-484. (https://doi.org/10.1126/science.1199214)

Wang S, Wei J, Fan Y, Ding H, Tian H, Zhou X \& Cheng L 2018 Progranulin is positively associated with intervertebral disc degeneration by interaction with IL-10 and IL-17 through TNF pathways. Inflammation 41 1852-1863. (https://doi.org/10.1007/ s10753-018-0828-1)

Wu S, Zang W, Li X \& Sun H 2011 Proepithelin stimulates growth plate chondrogenesis via nuclear factor-kappaB-p65-dependent mechanisms. Journal of Biological Chemistry 286 24057-24067. (https://doi.org/10.1074/jbc.M110.201368)

Yamamoto Y, Takemura M, Serrero G, Hayashi J, Yue B, Tsuboi A, Kubo H, Mitsuhashi T, Mannami K, Sato M, et al. 2014 Increased serum GP88 (Progranulin) concentrations in rheumatoid arthritis. Inflammation 37 1806-1813. (https://doi.org/10.1007/s10753-0149911-4)

Yamazaki H, Hiramatsu N, Hayakawa K, Tagawa Y, Okamura M, Ogata R, Huang T, Nakajima S, Yao J, Paton AW, et al. 2009 Activation of the Akt-NF-kappaB pathway by subtilase cytotoxin through the ATF6 branch of the unfolded protein response. Journal of Immunology 183 1480-1487. (https://doi.org/10.4049/jimmunol.0900017)

Yang D, Wang LL, Dong TT, Shen YH, Guo XS, Liu CY, Liu J, Zhang P, Li J \& Sun YP 2015 Progranulin promotes colorectal cancer proliferation and angiogenesis through TNFR2/Akt and ERK signaling pathways. American Journal of Cancer Research 5 3085-3097.

Yeung F, Hoberg JE, Ramsey CS, Keller MD, Jones DR, Frye RA \& Mayo MW 2004 Modulation of NF-kappaB-dependent transcription and cell survival by the SIRT1 deacetylase. EMBO Journal 23 2369-2380. (https://doi.org/10.1038/sj.emboj.7600244)

Yilmaz Y, Eren F, Yonal O, Polat Z, Bacha M, Kurt R, Ozturk O \& Avsar E 2011 Serum progranulin as an independent marker of liver fibrosis in patients with biopsy-proven nonalcoholic fatty liver disease. Disease Markers 31 205-210. (https://doi.org/10.3233/DMA-20110815)

Yoo HJ, Hwang SY, Hong HC, Choi HY, Yang SJ, Choi DS, Baik SH, Bluher M, Youn BS \& Choi KM 2013 Implication of progranulin and C1q/TNF-related protein-3 (CTRP3) on inflammation and atherosclerosis in subjects with or without metabolic syndrome. PLOS ONE 8 e55744. (https://doi.org/10.1371/journal. pone.0055744)

Yoshizaki T, Milne JC, Imamura T, Schenk S, Sonoda N, Babendure JL, Lu JC, Smith JJ, Jirousek MR \& Olefsky JM 2009 SIRT1 exerts antiinflammatory effects and improves insulin sensitivity in adipocytes. Molecular and Cellular Biology 29 1363-1374. (https://doi. org/10.1128/MCB.00705-08)

Youn BS, Bang SI, Kloting N, Park JW, Lee N, Oh JE, Pi KB, Lee TH, Ruschke K, Fasshauer M, et al. 2009 Serum progranulin concentrations may be associated with macrophage infiltration into omental adipose tissue. Diabetes 58 627-636. (https://doi. org/10.2337/db08-1147)

Received in final form 19 January 2020

Accepted 24 January 2020

Accepted Manuscript published online 24 January 2020 https://jme.bioscientifica.com https://doi.org/10.1530/JME-19-021 (c) 2020 Society for Endocrinology Published by Bioscientifica Ltd. Printed in Great Britain 